\title{
IMPORTÂNCIA DAS AULAS PRÁTICAS PARA APRENDIZADO DA DISCIPLINA DE MATERIAIS DE CONSTRUÇÃO II DO CURSO DE ENGENHARIA CIVIL DA UNIVERSIDADE ESTADUAL VALE DO ACARAÚ
}

\author{
DOI: 10.37702/2175-957X.COBENGE.2021.3755
}

Felipe Melo Carvalho - felipe.melo.7717@gmail.com

UNIVERSIDADE ESTADUAL VALE DO

Rua Euripedes Ferreira Gomes 652

62750-040 - Sobral - CE

Olívia de Moura Cordeiro - oliviacordeiro@hotmail.com

UNIVERSIDADE ESTADUAL VALE DO

Rua Dr. Manuel Joaquim Sem número

- Santana do Acaraú - CE

JUSCELINO CHAVES SALES - juscelinochaves@hotmail.com

UNIVERSIDADE ESTADUAL VALE DO ACARAÚ

RUA SOCORRO AZEVEDO, 150

60810-400 - FORTALEZA - CE

Resumo: As primeiras universidades que foram fundadas em todo o mundo principalmente na Europa só possuíam como finalidade o ensino. Com o passar dos séculos chegamos hoje aonde podemos dizer que as universidades têm que ter 0 ensino, a pesquisa, a extensão e a inovação. Quando se pergunta ao professor universitário onde ele trabalha se pergunta qual a sua instituição de ensino. Nos cursos de engenharia tanto as aulas teóricas como as práticas são de grande importante para os discentes. Já existe vários estudos mostrando a importância das aulas práticas realizadas em laboratório, na aprendizagem dos alunos de engenharia. $O$ presente trabalho mostra como as aulas práticas podem ajudar no desenvolvimento de conceitos científico. Concluiu-se que as aulas práticas influenciam o aprendizado do aluno e ajuda-o a fixar o conteúdo aprendido em sala de aula, na disciplina de Materiais de Construção II do curso de engenharia civil da Universidade Estadual Vale do Acaraú (UVA) localizada na cidade de Sobral no Estado do Ceará. 


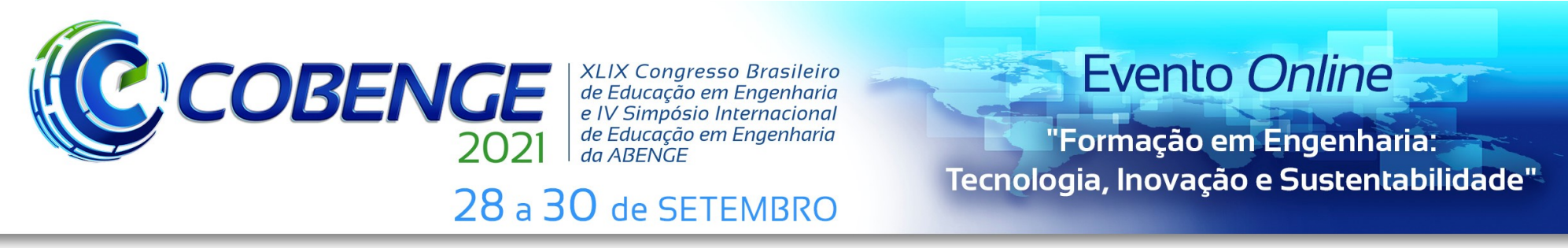

Palavras-chave: Engenharia Civil. Materiais de Construção II. Aulas práticas 
IMPORTÂNCIA DAS AULAS PRÁTICAS PARA APRENDIZADO DA DISCIPLINA DE MATERIAIS DE CONSTRUÇÃO II DO CURSO DE ENGENHARIA CIVIL DA UNIVERSIDADE ESTADUAL VALE DO ACARAÚ 


\section{INTRODUÇÃO}

Os conhecimentos teóricos repassados em sala de aula nem sempre são tão efetivos para que os alunos aprendam sobre alguns assuntos, às vezes, se faz necessário uma experiência prática para que ocorra a total absorção do conteúdo pelos discentes. As aulas práticas podem ajudar no desenvolvimento de conceitos científicos, além de permitir que os estudantes aprendam como abordar objetivamente o seu mundo e como desenvolver soluções para problemas complexos (LUNETTA, 1991).

As aulas práticas influenciam no maior engajamento do aluno, valoriza o trabalho em equipe e os coloca na frente de problemas e soluções. Quando compreende um conteúdo trabalhado em sala de aula, o aluno amplia sua reflexão sobre os fenômenos que acontecem à sua volta e isso pode gerar, consequentemente, discussões durante as aulas fazendo com que os alunos, além de exporem suas ideias, aprendam a respeitar as opiniões de seus colegas (LEITE, 2005).

Sabe-se que a maior parte da grade curricular dos cursos de Engenharia no Brasil contempla poucas disciplinas de laboratório. Tal fator contribui de forma negativa no aprendizado dos alunos, uma vez que aliar teoria à prática é uma forma de motivar o aluno, além de facilitar sua compreensão em relação ao tema estudado (SOARES, 2016).

Prestes (2016) através de um levantamento mostrou a importância de aulas práticas para o ensino superior de engenharia.

Podemos dizer que todos os cursos de engenharia necessitam de aulas práticas para um melhor aprendizado dos seus alunos em determinadas disciplinas e devem serem incluídas no projeto pedagógico do curso.

Na disciplina de Materiais de Construção II do curso de engenharia civil, os alunos da turma sempre passam por aulas práticas laboratoriais que os fazem colocar em prática o conhecimento abordado dentro de sala de aula. Esse é um momento importante para a fixação e reforço das informações passadas em sala de aula. Vale salientar que poucas são as disciplinas do curso que trazem aulas práticas, em que o aluno tem a oportunidade de aprender mais além do que o abordado em sala de aula.

Devemos utilizar metodologias de ensino para melhorar o aprendizado dos alunos dos cursos de engenharia civil. Além das aulas teóricas faz-se necessário fazer visitas técnicas as indústrias e obras de engenharia e as realizações de aulas práticas em determinadas disciplinas.

Este trabalho teve como principal objetivo demonstrar a importância das aulas práticas para o desenvolvimento do conhecimento dos alunos acerca de temas abordados em sala na disciplina de Materiais para construção II do curso de Engenharia Civil da Universidade Estadual Vale do Acaraú localizada na cidade de Sobral na região norte do estado do Ceará, a partir de um questionário aplicado com os alunos da turma no começo e no término das aulas práticas.

\section{METODOLOGIA}

O desenvolvimento da pesquisa se deu por meio de diversas etapas. A primeira etapa consistia em elaborar perguntas para fazerem parte de um questionário onde os alunos deveriam responder de 1 a 10 , sendo 1 para insatisfeito e 10 para muito satisfeito. As questões feitas diziam respeito a alguns tópicos e conceitos que os alunos viram em sala de aula com o professor, sendo que foram elaboradas cinco questões sobre os temas de sala de aula. A primeira era sobre como o grau de experiência que o aluno tem sobre o traço do concreto, a segunda sobre as etapas de confecção do concreto, a terceira sobre o ensaio para medir o slump do concreto, a quarta sobre a moldagem de corpos de prova de concreto utilizados para controle tecnológico, a quinta sobre a cura do concreto e como essa deve ser processada. E ainda foi questionada a opinião deles sobre a importância da prática para fixar e auxiliar 
no conhecimento dos assuntos abordados em sala na sexta pergunta e a sétima e última foi sobre a intenção do aluno em iniciar uma pesquisa científica. A segunda etapa foi colocar a pesquisa em execução com os discentes que cursavam a disciplina e fizeram parte das aulas práticas, para isso foi decidido que todas as perguntas fossem respondidas uma vez antes da primeira aula prática e outra vez após a última aula prática, podendo assim analisar o desenvolvimento e a opinião em tempos diferentes. Por fim, a terceira etapa consistia na análise dos resultados, onde eles foram discutidos pela equipe levando em conta a comparação das médias antes e depois das aulas práticas.

\section{REVISÃO BIBLIOGRÁFICA}

Pesquisadores de um curso de engenharia mecânica, baseado nas definições de engenharia, nas técnicas de criatividade e na experiência reportada, podem dizer, que os laboratórios dentro do curso de Engenharia, tem um papel fundamental na formação do aluno uma vez que permite, possibilita e aprimora a capacidade de tornar real o teórico, de tornar viável o problema e de se adaptar às mais diversas condições que se apresentarão quando do exercício da profissão (PEKELMAN, 2004).

Pesquisadores utilizaram ações inovadoras de ensino prático aplicado à graduação, desenvolvido na disciplina de Ciência dos Materiais para o curso de Engenharia Civil do IFTO/Palmas e constaram que a utilização de metodologias que aderem aulas práticas aliadas às tradicionais metodologias teóricas, se configuram como dispositivos potencialmente eficazes nessa transmissão de conhecimentos, visto que elas se tornam cúmplices nessa tarefa (BATISTA, 2017).

Pesquisadoras apresentaram uma alternativa de abordagem prática do conteúdo, ligado a área de ciência e tecnologia dos materiais de construção, tendo essas atividades contribuído positivamente na assimilação do conteúdo teórico e contribui para a compreensão da futura profissão de engenheiro civil de acordo com os alunos, de acordo com os alunos (ALVES, 2019).

Após as análises realizadas em laboratórios, como o Laboratório de Técnicas Construtivas, ficou bastante visível o aumento de compreensão e entendimento dos processos, quando se aplica aulas práticas. É totalmente perceptível a variação positiva na quantidade de alunos que alcançam um melhor domínio do conteúdo. Em todos os casos, houve um crescimento significativo nos níveis de compreensão após as aulas práticas. As aulas práticas contribuíram no processo de ensinoaprendizagem (AMORIM, 2019).

Uma aluna do $7^{\circ}$ período, do curso de engenharia civil da Unipac Lafaiete aprova as aulas práticas e ressalta que esta atividade reforça o aprendizado e traz mais segurança para o aluno. "Tudo que a gente aprende na teoria fica um pouco vazio e quando a gente vem para aula prática tem uma melhor ideia, sente melhor aquilo que o professor explicou no papel. É o momento em que entendemos a importância daqueles dados e como vamos utilizá-los" (JORNAL CORREIO DA CIDADE, 2021).

Através das aulas práticas, os alunos conseguem sair do conceito um pouco abstrato (formação da imagem por meio da imaginação) das coisas que estudam em sala de aula, e passam a entender claramente como as coisas realmente ocorrem durante o processo estudado (formação visual das imagens) (UNIVIÇOSA, 2017).

A importância das aulas práticas é inquestionável e deveria ocupar lugar central no ensino. No entanto, o aspecto formativo das atividades práticas experimentais tem sido negligenciado, muitas vezes, ao caráter superficial, mecânico e repetitivo em detrimento ao aprendizado teórico-prático que se mostre dinâmico e significativo. (PRESTES, 2016).

\section{3}

\section{RESULTADOS}

A pesquisa contou com a participação de 26 alunos que responderam as sete perguntas propostas antes e depois. Para a primeira pergunta foi obtido uma média de 3,08 para antes e 8,19 para depois, mostrando uma evolução de $166,25 \%$. Para a segunda pergunta teve-se uma média de 
4,62 para antes e 8,69 para depois, sendo assim um aumento de 88,33\%. Já a terceira pergunta apresentou resultados de 3,85 para antes e 8,77 para depois evidenciando uma melhoria de $128 \%$. Na quarta pergunta os resultados apontaram para 3,88 antes e 8,85 depois, demonstrando $127,72 \%$ de aumento. Para a quinta pergunta obteve-se 4,23 antes e 8,32 depois com um aumento de 96,65\%. Já na sexta pergunta o resultado obtido foi de 8,42 para antes e 9,85 para depois com um aumento de $16,89 \%$. Na sétima e última os resultados foram de 5,27 para antes e 8,04 para depois, com aumento de 52,55\%. A Tabela 1 mostra os resultados da pesquisa onde foram entrevistados 26 alunos do quinto semestre do curso de engenharia civil da Universidade Estadual Vale do Acaraú.

Tabela 1: Resultados da pesquisa onde foram entrevistados 26 alunos.

\begin{tabular}{|c|c|c|c|c|}
\hline & & & Diferença & Aumento \% \\
\hline \multirow{2}{*}{ Pergunta 1} & Média antes & 3,08 & \multirow{2}{*}{5,11} & \multirow{2}{*}{166,25} \\
\hline & Média depois & 8,19 & & \\
\hline \multirow{2}{*}{ Pergunta 2} & Média antes & 4,62 & \multirow{2}{*}{4,07} & \multirow{2}{*}{88,33} \\
\hline & Média depois & 8,69 & & \\
\hline \multirow{2}{*}{ Pergunta 3} & Média antes & 3,85 & \multirow{2}{*}{4,92} & \multirow{2}{*}{128,00} \\
\hline & Média depois & 8,77 & & \\
\hline \multirow{2}{*}{ Pergunta 4} & Média antes & 3,88 & \multirow{2}{*}{4,97} & \multirow{2}{*}{127,72} \\
\hline & Média depois & 8,85 & & \\
\hline \multirow{2}{*}{ Pergunta 5} & Média antes & 4,23 & \multirow{2}{*}{4,09} & \multirow{2}{*}{96,65} \\
\hline & Média depois & 8,32 & & \\
\hline \multirow{2}{*}{ Pergunta 6} & Média antes & 8,42 & \multirow{2}{*}{1,43} & \multirow{2}{*}{16,89} \\
\hline & Média depois & 9,85 & & \\
\hline \multirow{2}{*}{ Pergunta 7} & Média antes & 5,27 & \multirow{2}{*}{2,77} & \multirow{2}{*}{52,55} \\
\hline & Média depois & 8,04 & & \\
\hline
\end{tabular}

Fonte: Própria, 2019.

A Tabela 2 mostra os resultados da pesquisa aonde foram com somente os cinco (5) primeiros alunos, mostrando a nota das respostas variando de zero (0) até dez (10) atribuídas. A resposta zero o aluno está totalmente insatisfeito.

Vale ressaltar que a Tabela 2 só estar mostrando 5 (cinco) alunos de um total de 26 alunos e só um aluno, o primeiro (1) de todos os 26 alunos respondeu zero (0) antes e dez (10) muito satisfeito na pergunta seis (6). 
Tabela 2: Resultados da pesquisa aonde foram com somente os cinco (5) primeiros alunos

\begin{tabular}{c|c|c|c|c|c|c} 
& Na aluno & 1 & 2 & 3 & 4 & 5 \\
\hline \multirow{2}{*}{ Perg 1} & Nota antes & 4 & 3 & 0 & 0 & 0 \\
\cline { 2 - 7 } & Nota dps & 8 & 9 & 8 & 9 & 7 \\
\hline \multirow{2}{*}{ Perg 2} & Nota antes & 7 & 1 & 2 & 6 & 0 \\
\cline { 2 - 7 } & Nota dps & 8 & 9 & 9 & 10 & 8 \\
\hline \multirow{2}{*}{ Perg 3 } & Nota antes & 7 & 1 & 2 & 6 & 0 \\
\cline { 2 - 7 } & Nota dps & 9 & 8 & 8 & 10 & 5 \\
\hline \multirow{2}{*}{ Perg 4 } & Nota antes & 7 & 1 & 1 & 5 & 0 \\
\cline { 2 - 7 } & Nota dps & 9 & 8 & 8 & 9 & 8 \\
\hline \multirow{2}{*}{ Perg 5 } & Nota antes & 6 & 1 & 2 & 6 & 0 \\
\cline { 2 - 7 } & Nota dps & 9 & 8 & 8 & 9 & 7 \\
\hline \multirow{2}{*}{ Perg 6 } & Nota antes & 0 & 8 & 8 & 9 & 10 \\
\cline { 2 - 7 } & Nota dps & 10 & 10 & 10 & 10 & 10 \\
\hline \multirow{2}{*}{ Perg 7 } & Nota antes & 7 & 2 & 6 & 6 & 5 \\
\cline { 2 - 7 } & Nota dps & 10 & 7 & 9 & 9 & 7 \\
\hline
\end{tabular}

Fonte: Própria, 2019.

A pergunta 6 mostrou que nove alunos dos 26 alunos (total) tiraram a mesma pontuação (10) da nota antes e depois das aulas práticas, onde neste caso temos a menor diferença $(1,43)$ e o menor aumento em percentagem $(16,89 \%)$.

\section{DISCUSSÃO}

Os resultados coletados demonstraram que em todas as questões abordadas ocorreu uma notável melhoria, o aumento geral da média dos resultados foi bem evidente. Isso comprova que as aulas práticas na disciplina de Materiais para Construção II auxiliam na fixação do conteúdo explicado em sala de aula. Ademais também foi comprovado um aumento da opinião dos alunos em relação à importância do ensino prático dentro da disciplina para auxiliar o ensino teórico, questão essa discutida na sexta pergunta. Também se obteve um aumento considerável em relação ao incentivo em iniciar uma pesquisa científica, demonstrando que muitas vezes a vontade de se fazer uma pesquisa nasce dentro das dinâmicas e aulas práticas ocorridas durante as mais variadas disciplinas, com foco especial nesse caso para a disciplina de Materiais de Construção II.

É de grande importância as aulas práticas nos laboratórios durante a graduação em engenharia civil, como também em todas as engenharias, pois as aulas práticas auxiliaram no processo de ensinoaprendizagem.

\section{CONCLUSÕES}

Concluiu-se então que as aulas práticas influenciam o aprendizado do aluno e ajuda-o a fixar o conteúdo aprendido em sala aula. Ademais, elas conseguem despertar nos alunos um interesse pelo ramo científico, a partir do pressuposto que a busca por soluções, as dúvidas, a inovação e a criatividade se tornam mais visíveis dentro das aulas práticas. O desenvolvimento delas é de suma importância para os alunos, devendo ser necessária na metodologia de ensino da maioria das disciplinas ao longo do curso de engenharia civil. 


\section{REFERÊNCIAS}

AMORIM, Bill Clinton Torquato; BOES, Jeferson Spiering. Contribuição de aulas práticas no ensino/aprendizagem de técnicas construtivas: uma visão do aluno. XLVIII Congresso Brasileiro de Ensino de Engenharia, Fortaleza, 2019. Disponível em:< http://www.abenge.org.br/sis_artigos.php>. Acesso em: 27 mai. 2020.

ALVES, Rafaelly Bezerra; COSTA, Heloina Nogueira. Abordagem prática no ensino de engenharia. XLVIII Congresso Brasileiro de Ensino de Engenharia, Fortaleza, 2019. Disponível em:<http://www.abenge.org.br/sis_artigos.php>. Acesso em: 27 mai. 2020.

BATISTA, Willian Gomes et al. A importância da Metodologia Prática aplicada à Engenharia como fator inerente à aquisição do conhecimento profissional: o caso da disciplina de Ciência dos Materiais. 8 Jornada de Iniciação Cientifica e Extensão do IFTO- Instituto Federal do Tocantins, 2017. Disponível em: < http://propi.ifto.edu.br/ocs/index.php/jice/8jice/paper/viewFile/8621/3879>. Acesso em: 27 mai. 2020.

JORNAL CORREIO DA CIDADE. Aulas práticas auxiliam na formação dos engenheiros civis na Unipac Lafaiete. 2021. Disponível em: http://www.jornalcorreiodacidade.com.br/noticias/13546-aulas-praticas-auxiliam-na-formacao-dos-engenheiros-civis-na-unipac-lafaiete>. Acesso em: 20 mai. 2021.

LEITE, Ariana Cristina Sousa; SILVA, Poliana Alves Borges; VAZ, Ana Cristina Ribeiro. A importância das aulas práticas para alunos jovens e adultos: uma abordagem investigativa sobre a percepção dos alunos do PROEF II, Ens. Pesqui. Educ. Ciênc. (Belo Horizonte) vol.7 n.3 Belo Horizonte,2005.

LUNETTA, V. N. Atividades práticas no ensino da Ciência. Revista Portuguesa de Educação, v. 2, n. 1, p. 81-90, 1991.

PEKELMAN, Hélio; MELO JR, Antônio Gonsalves. 2004. Antônio Gonsalves. A importância dos laboratórios no ensino de engenharia mecânica. XXXII Congresso Brasileiro de Ensino de Engenharia, Brasília, 2004. Disponível em: <http://www.abenge.org.br/cobenge/arquivos/15/artigos/01_219.pdf>. Acesso em: 27 mai. 2020.

PRESTES, Ethielle., RODRIGUES, Luciana Machado. Levantamento sobre a importância de aulas práticas para o ensino superior de engenharia. v. 8 n. 1 (2016): Anais do $8^{\circ}$ Salão Internacional de Ensino, Pesquisa e Extensão da UNIPAMPA: Salão de Ensino. Disponível em: < https://periodicos.unipampa.edu.br/index.php/SIEPE/article/view/84976> . Acesso em: 20 mai. 2021.

SOARES, Darlane Wellen Freitas et al. Importância de aulas práticas para os cursos de engenharia: consolidação de conhecimento e motivação. In: Anais da VII Mostra de Pesquisa em Ciência e Tecnologia DeVry Brasil. Fortaleza. 2016. Disponível em: < https://www.even3.com.br/anais/viimostradevry/30431-importancia-de-aulas-praticas-para-oscursos-de-engenharia--consolidacao-de-conhecimento-e-motivacao/\# >. Acesso em: 20 mai. 2021.

UNIVIÇOSA, 2017. A importância da realização de aulas práticas no curso de Engenharia Química. Disponível em: <https://univicosa.com.br/uninoticias/noticias/a-importancia-das-aulaspraticas-no-curso-de-engenharia-quimica>. Acesso em: 20 mai. 2021. 


\title{
IMPORTANCE OF PRACTICAL CLASSES FOR LEARNING THE DISCIPLINE OF MATERIALS FOR CONSTRUCTION II OF THE CIVIL ENGINEERING COURSE OF THE VALE DO ACARAÚ STATE UNIVERSITY
}

\begin{abstract}
The first universities that were founded all over the world, mainly in Europe, had only the purpose of teaching. Over the centuries we have reached today where we can say that universities must have teaching, research, extension and innovation. When you ask the university professor where he works, you ask him what his educational institution is. In engineering courses, both theoretical and practical classes are of great importance for students. There are already several studies showing the importance of practical classes held in the laboratory, in the learning of engineering students. The present work shows how practical classes can help in the development of scientific concepts. It was concluded that the practical classes influence the student's learning and help him to fix the content learned in the classroom, in the discipline of Construction Materials II of the civil engineering course of the Universidade Estadual Vale do Acaraú (UVA) located in the city of Sobral in the State of Ceará.
\end{abstract}

Keywords: Civil engineering. Construction materials II. Practical classes. 